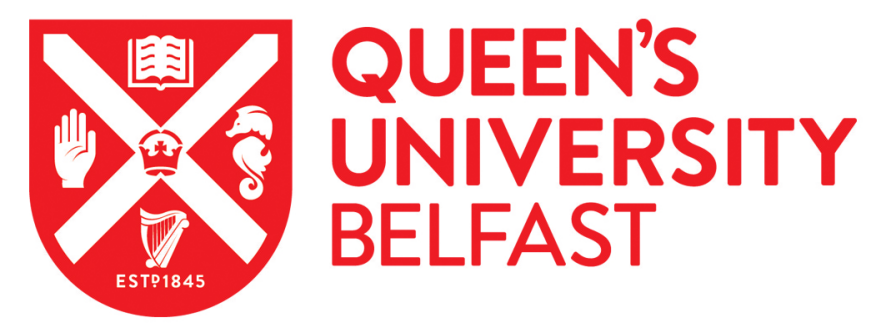

\title{
Using an integrated conceptual framework to investigate parents' HPV vaccine decision for their daughters and sons
}

\author{
Shapiro, G. K., Tatar, O., Amsel, R., Prue, G., Zimet, G. D., Knauper, B., \& Rosberger, Z. (2018). Using an \\ integrated conceptual framework to investigate parents' HPV vaccine decision for their daughters and sons. \\ Preventive Medicine, 116, 203-210. https://doi.org/10.1016/j.ypmed.2018.09.017
}

Published in:

Preventive Medicine

Document Version:

Peer reviewed version

Queen's University Belfast - Research Portal:

Link to publication record in Queen's University Belfast Research Portal

\section{Publisher rights}

Copyright 2018 Elsevier.

This manuscript is distributed under a Creative Commons Attribution-NonCommercial-NoDerivs License

(https://creativecommons.org/licenses/by-nc-nd/4.0/), which permits distribution and reproduction for non-commercial purposes, provided the author and source are cited.

\section{General rights}

Copyright for the publications made accessible via the Queen's University Belfast Research Portal is retained by the author(s) and / or other copyright owners and it is a condition of accessing these publications that users recognise and abide by the legal requirements associated with these rights.

Take down policy

The Research Portal is Queen's institutional repository that provides access to Queen's research output. Every effort has been made to ensure that content in the Research Portal does not infringe any person's rights, or applicable UK laws. If you discover content in the Research Portal that you believe breaches copyright or violates any law, please contact openaccess@qub.ac.uk. 
Using an integrated conceptual framework to investigate parents' HPV vaccine decision for their daughters and sons

Gilla K. Shapiro,,${ }^{1,2,}$, Ovidiu Tatar, ${ }^{2}$ Rhonda Amsel, ${ }^{1}$ Gillian Prue, ${ }^{3}$ Gregory D. Zimet, ${ }^{4}$ Barbel Knauper, ${ }^{1}$ Zeev Rosberger. ${ }^{1,2,5,6}$.

${ }^{1}$ Department of Psychology, McGill University, 1205 Dr. Penfield Avenue, Montreal, Quebec, H3A 1B1

${ }^{2}$ Lady Davis Institute for Medical Research, Jewish General Hospital, 4333 Côte St-Catherine Road, Montreal, Quebec, H3T 1E4

${ }^{3}$ School of Nursing and Midwifery, Medical Biology Centre, Queen's University Belfast, 97 Lisburn Road, Belfast BT9 7BL, Northern Ireland

${ }^{4}$ Section of Adolescent Medicine, Department of Pediatrics, Indiana University School of Medicine, Indianapolis, Indiana, USA

${ }^{5}$ Louise Granofsky Psychosocial Oncology Program, Jewish General Hospital, 4333 Côte StCatherine Road, Montreal, Quebec, H3T 1E4

${ }^{6}$ Departments of Psychiatry and Oncology, McGill University, 1205 Dr. Penfield Avenue, Montreal, Quebec, H3A 1B1.

Corresponding author: Gilla K. Shapiro, Department of Psychology, McGill University, 1205 Dr. Penfield Avenue, Montreal, Quebec, H3A 1B1; telephone: +1-514-340-8222, ext. 3978; Email: gilla.shapiro@mail.mcgill.ca

Abstract Word Count: 247 words

Manuscript Word Count: 3,554 


\begin{abstract}
Despite being an effective cancer prevention strategy, human papillomavirus (HPV) vaccination in Canada remain suboptimal. This study is the first to concurrently evaluate HPV vaccine knowledge, attitudes, and the decision-making stage of Canadian parents for their school-aged daughters and sons. Data were collected through an online survey from a nationally representative sample of Canadian parents of 9-16 year old children from August to September 2016. Measures included socio-demographics, validated scales to assess HPV vaccine knowledge and attitudes (using the Health Belief Model), and parents' HPV vaccination adoption stage using the Precaution Adoption Process Model (PAPM; six stages: unaware, unengaged, undecided, decided not, decided to, or vaccinated). 3,779 parents' survey responses were analyzed (1,826 parents of sons and 1,953 parents of daughters). There was a significant association between child's gender and PAPM stage of decision-making, with parents of boys more likely to report being in earlier PAPM stages. In multinomial logistic regression analyses parents of daughters (compared to sons), parents of older children, and parents with a health care provider recommendation had decreased odds of being in any earlier PAPM stage as compared to the last PAPM stage (i.e. vaccinated). Parents who were in the 'decided not to vaccinate' stage had significantly greater odds of reporting perceived vaccine harms, lack of confidence, risks, and vaccine conspiracy beliefs. Future research could use these findings to investigate theoretically informed interventions to specifically target subsets of the population with particular attention towards addressing knowledge gaps, perceived barriers, and concerns of parents.
\end{abstract}

\title{
Keywords
}

Human papillomavirus vaccination; vaccine uptake; vaccine intentions; vaccine hesitancy; determinants of health; gender; health behaviour change; Health Belief Model; Precaution Adoption Process Model 


\section{Highlights}

- Canadian parents report suboptimal HPV vaccination rates for their children

- An integrated conceptual framework used the Health Belief Model (HBM) and Precaution Adoption Process Model (PAPM)

- Parents of boys were more likely to report being in earlier PAPM stages

- PAPM stages were associated with different psychosocial correlates

- Tailored health messages could be developed to target individuals at different PAPM stages 


\section{Introduction}

Human papillomavirus (HPV) can cause a number of anogenital and oropharyngeal cancers in men and women. ${ }^{1,2}$ To prevent morbidity and mortality, three vaccines have been licensed and recommended for use. ${ }^{3,4}$ Currently, over 80 countries have implemented national HPV vaccination programs. ${ }^{1,5,6}$ In Canada, provinces and territories have implemented publicly funded school-based HPV vaccine programs. All Canadian jurisdictions implemented programs for girls, from 2007-2010. ${ }^{7,8}$ As of 2018, all jurisdictions also offer programs for boys in schools $;{ }^{9}$ however, the roll out of these programs (since 2013) has been staggered and HPV vaccination rates in Canada remain suboptimal. ${ }^{3,8,10}$

Because HPV vaccination targets children, ${ }^{3}$ parental acceptance is critical to ensuring uptake. Previous research has indicated common themes associated with uptake, such as the importance of parents believing in the benefits of vaccination and perceiving few barriers. ${ }^{11,12}$ Unsurprisingly, parents are less likely to vaccinate their children if they are not aware of, or do not know enough about, HPV vaccination. Parents are also less likely to vaccinate their child if they believe that HPV vaccination can cause harm, or that vaccination is not accessible or affordable. ${ }^{13}$ Furthermore, positive attitudes towards vaccines in general are related to HPV vaccine acceptance. ${ }^{14,15}$ Notably, a strong health care provider (HCP) recommendation significantly improves parental vaccine acceptance. ${ }^{4,11,16}$ Other social influences, including by a partner, family, friends, or online social network, can also influence parents' decision. ${ }^{13,16-18}$

It is likely that these factors have varying impact on parents depending on where they are in the decision-making process, which is obscured in much previous research investigating vaccination as a binary outcome (vaccinated or not). Literature on vaccine hesitancy highlights many reasons a parent may delay or refuse vaccination for their child. ${ }^{19}$ A theoretical stage-based model, the Precaution Adoption Process Model (PAPM), allows for a nuanced examination of which modifying factors and individual health beliefs are important for each stage of decisionmaking (Figure 1). ${ }^{20-22}$ The PAPM identifies six stages involved in making a health decision and clarifies what factors lead individuals to move from one health behaviour decision-making stage to the next ${ }^{23}$..A stage-based understanding of HPV vaccine decision-making is important for identifying the psychosocial correlates for each stage and how to best intervene for parents at different stages. Nevertheless, few studies have examined the stages of HPV vaccine decision- 
making in college students and parents of only boys, ${ }^{16,24-26}$ and no study has compared the stages of decision-making of parents of girls to parents of boys. Previous studies have found that college students and parents of boys were in the earliest stages of HPV vaccine decisionmaking. ${ }^{16,24-26}$ Given HPV vaccine programs and policies have differentially targeted boys and girls, it is important to examine differences in decision-making stage between parents of girls and boys.

This study will identify and compare parents' stage of decision-making by gender for their school-aged daughters and sons, examine differences in parents' HPV vaccine knowledge and attitudes by PAPM stage, and investigate the psychosocial correlates of parents' PAPM stages.

\section{Methods}

\section{Survey design and participants}

Details of the methodology are presented in the protocol paper. ${ }^{20}$ This study used a crosssectional design to collect self-reported online survey data from a national sample of Canadian parents. Data presented here were part of a larger two-wave protocol and were collected from August 17 to September 11, 2016 (i.e. Time one). All Canadian jurisdictions at this time had publicly funded, school-based HPV vaccination programs for girls but only three provinces (i.e. Alberta, Prince Edward Island, and Nova Scotia) had programs for boys.

This study targeted parents and/or guardians (hereafter referred to as parents) of 9-16 year-old boys and girls. Parents with more than one child were asked to answer the questionnaire in reference to the child who had the most recent birthday to ensure randomization. The online survey was offered in English and French (i.e. Canada's two official languages). Participants were recruited using, Leger-The Research Intelligence Group, which maintains a nationally representative panel of 400,000 Canadians. ${ }^{27}$ This study received Research Ethics Board approval from the Research Review Office, Integrated Health and Social Services University Network for West-Central Montreal (CODIM-FLP-16-219). ${ }^{20}$ 


\section{Measures}

The dependent variable was parents' PAPM stage, which categorizes parents' stage of decision-making regarding HPV vaccination into six stages (Figure 1). ${ }^{21}$

Potential psychosocial predictors of HPV vaccine decision-making included sociodemographics, HCP recommendation, as well as validated scales to assess HPV and HPV vaccine knowledge, HPV vaccine attitudes, and general vaccine attitudes. HCP recommendation was assessed by asking parents, 'did a health care provider (e.g. a doctor, pediatrician, or nurse) recommend that [child's name] receive the HPV vaccine within the last 12 months?'. Parents were only administered this question if they had answered affirmatively that they had seen a HCP and discussed their child receiving the HPV vaccine with a HCP.

Two validated scales were used to measure parents' knowledge of HPV and HPV vaccine. ${ }^{28,29}$ The 23-item HPV General Knowledge Scale $(\alpha=.94)$ and the 11-item HPV Vaccine Knowledge (VK) Scale ( $\alpha=.88$ ) (Appendix 1). To each item, respondents answered 'true', 'false', or 'don't know', for which a total score was calculated based on correct answers (higher scores indicate greater knowledge on both scales).

HPV vaccine attitudes were assessed using constructs from the Health Belief Model (HBM) including perceived benefits of, and barriers to, HPV vaccination; perceived severity of, and susceptibility to, HPV infection and disease; external influences prompting HPV vaccine uptake (i.e. cues to action), and the ability to exert change (i.e. self-efficacy). Sub-scales from the psychometrically validated HPV vaccination Attitudes and Beliefs Scale (HABS) were used to evaluate constructs from the HBM using a 7-point Likert-type rating scale ranging from 1 (strongly disagree) to 7 (strongly agree). ${ }^{29}$ Sub-scales were evaluated for internal consistency using Cronbach's $\alpha$. HBM constructs, assessed using HABS subscales, included perceived susceptibility of child to HPV and its consequences ( 3 items, $\alpha=.92$ ), perceived severity of HPV and its consequence ( 3 items, $\alpha=.84$ ), perceived benefits of HPV vaccine (10 items, $\alpha=.94$ ), perceived barriers to HPV vaccine ( 6 items to measure harms, $\alpha=.93 ; 4$ items to measure accessibility, $\alpha=.79$; and 3 items to measure affordability, $\alpha=.87$ ), cues to action ( 8 items, $\alpha=.91$ ), and self-efficacy (4 items $\alpha=.89$ ) (Appendix 1). ${ }^{1}$

\footnotetext{
${ }^{1}$ All scales are subscales the HABS except self-efficacy, which is a construct of the HBM but was not included as a subscale in the HABS.
} 
General vaccine attitudes were assessed using two psychometrically validated scales: the Vaccine Conspiracy Beliefs Scale (VCBS) and the Vaccine Hesitancy Scale (VHS). ${ }^{14,15}$ The VCBS has seven items assessed on a 7-point Likert-type rating scale $(\alpha=.95)$. The VHS was developed by the World Health Organization Sage Working Group on Vaccine Hesitancy, ${ }^{30}$ and psychometrically validated by our research group. ${ }^{15}$ The VHS was found to have two underlying factors (i.e. 'lack of confidence', $\alpha=.92$; and 'risks', $\alpha=.64$ ) and items are assessed on a 5-point Likert-type rating scale (Appendix 1).

\section{Analysis}

This study reports parents' HPV vaccine decision-making in percentages based on the six PAPM stages. For assessing significant differences in PAPM stage based on child's gender, a chi-square test was used.

To examine differences between reported vaccine knowledge and attitudes by PAPM stage, one-way ANOVA and Tukey Honest Significant Difference (HSD) post-hoc tests were conducted.

Multinomial logistic regression analyses were used to calculate the odds ratios of being in one of the first five PAPM stages compared to PAPM stage 6 (i.e. vaccinated, reference category). PAPM stage was the dependent variable. First, we conducted bivariate multinomial logistic regression analyses and estimated the associations for each independent variable individually. Subsequently, we performed multivariate multinomial logistic regression analyses by including 14 independent variables in a single model. In order to select variables that would ensure the most parsimonious and theory-driven multivariate model, variables were included based on attitudes predicted to be associated with behavioural change (according to the HBM) and significant modifying factors in the literature (see Figure 1). ${ }^{16,31}$ Odds ratios and 95\% confidence intervals (CI) were calculated. To assess multicollinearity of the multivariate multinomial logistic regression models, the Variation Inflation Factor (VIF) was calculated for all predictors. Model fit diagnostics were reported based on following criteria: (a) Cox-Snell $\mathrm{R}^{2}$, (b) Cragg-Uhler $\mathrm{R}^{2}$, and (c) McFadden $\mathrm{R}^{2}$.

Statistical analyses were performed using IBM SPSS V.23 and R 3.3.2. 


\section{Results}

\section{Sample Demographics}

A total of 4,606 parents completed the survey. The response rate, calculated based on completion by participants who initiated the questionnaire $(N=6,789)$ was $67.9 \%$. Overall, 827 (18.0\%) participants were excluded as these participants were detected to be inattentive or unmotivated respondents based on data cleaning (i.e. the use of two bogus items and index of psychometric synonyms). ${ }^{20}$ Sociodemographic characteristics for the final sample $(N=3,779)$ are presented in Table 1 . At the time of data collection, only $7 \%$ were parents of boys living in provinces where there was a publicly funded HPV vaccine program for boys available $(n=252)$ and fewer still would have been eligible for the program depending upon their child's age.

\section{Identifying Canadian parents' stage of decision-making by child's gender}

Table 2 shows the numbers of parents of boys and parents of girls across the six PAPM stages. HPV vaccine uptake of Canadian children was low, with only $801(41.0 \%)$ parents of girls reporting that their daughters were vaccinated and only $160(8.8 \%)$ parents of boys reporting that their sons were vaccinated. There was a significant and large association between child's gender and PAPM stage of decision making $\left(\chi^{2}(5)=735.25, p<.001, \varphi_{c}=.44\right)$ with parents of boys more likely to be in earlier stages. ${ }^{32}$

\section{Comparison of knowledge and attitudes for HPV vaccine PAPM stages}

One-way ANOVA found that there was a significant effect of PAPM stage on all vaccine knowledge and attitude scales (Table 3). The greatest effect sizes were for cues to action, benefits, and barriers-harms.

Post hoc analyses found that knowledge (both HPV vaccine knowledge and HPV general knowledge) was significantly lower for PAPM stages 1-3 (unaware, unengaged, and undecided) compared to later PAPM stages. In addition, parents who were unaware reported significantly 
lower perceived vaccine affordability compared to parents who were unengaged and undecided, while parents who were unaware and unengaged reported significantly lower perceived harms and VHS-risk compared to parents who were undecided.

Parents who decided not to vaccinate (Stage 4) significantly differed from all other PAPM stages on all scales except barriers-not accessible, self-efficacy, and knowledge scales (VK and GK); however, on these four scales, parents who decided not to vaccinate responded similarly to parents who decided to vaccinate or already vaccinated their child (Stages 5 and 6).

Parents who decided to vaccinate their child (Stage 5) reported significantly higher perceived benefits, greater perceived barriers of accessibility and affordability, and fewer cues to action compared to those who already vaccinated their child (Stage 6).

\section{Examination of correlates of PAPM stage}

The bivariate and multivariate multinomial logistic regression analyses of parents' PAPM stage can be found in Tables 4 and 5, respectively. Appendix 2 contains exploratory analyses of additional variables as well as all analyses conducted separately for parents of boys and girls. All earlier stages of PAPM were compared to the reference group (Stage 6-Vaccinated).

\section{Bivariate multinomial logistic regression}

Parents of daughters, older children, and parents with a HCP recommendation had decreased odds of being in any earlier PAPM stage as compared to the last PAPM stage (i.e. vaccinated). Higher HPV vaccine knowledge was significantly associated with decreased odds of being unaware, unengaged, undecided, or decided to vaccinate.

Parents who had decided not to vaccinate their child had significantly stronger vaccine conspiracy beliefs $(\mathrm{OR}=3.10 ; 95 \%$ CI 2.78;3.46), lack of confidence in vaccines $(\mathrm{OR}=9.21 ; 95 \%$ CI 7.50;11.31), and higher perception of vaccine risks (OR=5.19; 95\% CI 4.38;6.16) compared to parents who vaccinated their child.

Parents living in provinces with HPV vaccination programs for boys had significantly lower odds of being unaware $(\mathrm{OR}=0.34 ; 95 \% \mathrm{CI} 0.24 ; 0.48)$, unengaged $(\mathrm{OR}=0.49 ; 95 \% \mathrm{CI}$ $0.34 ; 0.70)$, or undecided (OR=0.50; 95\% CI 0.37;0.67). Further analysis by child's gender indicated that this effect was not significant in the model examining parents of girls; however, 
parents of boys living in provinces with HPV vaccine funding for boys had significantly lower odds of being in any earlier PAPM stage compared to vaccinated (Tables B4 and B7).

\section{Multivariate multinomial logistic regression}

Parents of daughters and older children had significantly decreased odds of reporting that their child was in any earlier PAPM stage compared to vaccinated. Parents answering the survey in French had lower odds of being unengaged (AOR=0.67; 95\% CI 0.47;0.97), undecided $(\mathrm{AOR}=0.61 ; 95 \% \mathrm{CI} 0.44 ; 0.84)$ and decided to vaccinate $(\mathrm{AOR}=0.51 ; 95 \% \mathrm{CI} 0.38 ; 0.67)$.

Parents who received a HCP recommendation for HPV vaccination had lower odds of being unaware $(\mathrm{AOR}=0.04 ; 95 \% \mathrm{CI} 0.01 ; 0.16)$, unengaged $(\mathrm{AOR}=0.21 ; 95 \% \mathrm{CI} 0.10 ; 0.43)$, undecided $(\mathrm{AOR}=0.55 ; 95 \% \mathrm{CI} 0.36 ; 0.84)$, and decided not to vaccinate $(\mathrm{AOR}=0.30 ; 95 \% \mathrm{CI}$ $0.15 ; 0.61)$. There was no significant difference between the decided to vaccinate and vaccinated groups. Higher HPV vaccine knowledge was significantly associated with decreased odds of being unaware $(\mathrm{AOR}=0.75 ; 95 \% \mathrm{CI} 0.71 ; 0.79)$, unengaged $(\mathrm{AOR}=0.86 ; 95 \% \mathrm{CI} 0.81 ; 0.91)$, and increased odds of having decided not to vaccinate ( $\mathrm{AOR}=1.12 ; 95 \%$ CI $1.04 ; 1.22$ ).

A higher perception of susceptibility and severity were only significantly associated with decreased odds of being in the stage decided not to vaccinate (AOR $=0.68 ; 95 \%$ CI $0.55 ; 0.84$ and $\mathrm{AOR}=0.66 ; 95 \% \mathrm{CI} 0.54 ; 0.80)$. Higher perception of the benefits of vaccination was significantly associated with increased odds of being unaware (AOR=1.89; 95\% CI 1.48;2.41), unengaged $(\mathrm{AOR}=1.62 ; 95 \% \mathrm{CI} 1.26 ; 2.08)$, undecided $(\mathrm{AOR}=1.40 ; 95 \% \mathrm{CI} 1.12 ; 1.74)$ and decided to vaccinate $(\mathrm{AOR}=2.10 ; 95 \% \mathrm{CI} 1.72 ; 2.55)$, and decreased odds of being decided not to vaccinate $(\mathrm{AOR}=0.60 ; 95 \%$ CI $0.45 ; 0.81)$.

Compared to those who vaccinated their child, parents in all other stages had significantly increased odds of reporting greater barriers (including affordability, accessibility, and perceived harms). However, perceived accessibility of parents who vaccinated their children did not differ significantly with parents who were undecided, decided not to vaccinate their child, or decided to vaccinate their child. Of note, parents who had a higher score on perceived harms had higher odds of being in Stage 4 (decided not to vaccinate) ( $\mathrm{AOR}=3.50 ; 95 \%$ CI 2.85;4.28). Greater perceived influence of others (cues to action) was associated with lower odds of being in any of the earlier stages (compared to vaccinated) (AOR range of 0.20 to 0.51 ). 


\section{Discussion}

This study examined six distinct stages of HPV vaccine decision-making using the PAPM framework in a national survey of Canadian parents of 9-16 year-old boys and girls. Only $41.0 \%$ of girls and $8.8 \%$ of boys were in the final PAPM stage (Stage 6-Vaccinated). This is a lower proportion of vaccinated children than reported by other Canadian studies, ${ }^{3,33}$ which may be due to this study's design, which included data from jurisdictions without male HPV vaccination programs during data collection, relied on parental report of vaccination status, and evaluated a larger age range of children (including children before they were offered the HPV vaccine in funded school-based programs).

In a 2014 study using the PAPM to examine Canadian parents of boys, the majority of parents were unaware of HPV vaccination for their sons (Stage 1, 57.0\%), while exceptionally few had decided to vaccinate their son (Stage 5, 5.0\%) or had sons who had received the HPV vaccine (Stage 6,1.1\%). ${ }^{16}$ Data from the present study indicates that two years later and with two additional Canadian jurisdictions with male HPV vaccine programs (Alberta and Nova Scotia), fewer parents were unaware (25.6\%), and more parents had decided to vaccinate $(19.1 \%)$ or already vaccinated (8.8\%) their son (Table 2). By comparison, a survey of parents of boys conducted around the same time in the UK (when there was no funded program for boys) found that $46.8 \%$ were unaware. ${ }^{34}$ This emphasizes the importance of publicly funded vaccine programs and the associated educational campaigns in increasing awareness and uptake. ${ }^{35-37}$

Two further studies have used the PAPM to evaluate HPV vaccine decision-making. ${ }^{26,38}$ Though these studies were conducted in college students, both found males to be overwhelmingly unaware or unengaged (90\% or $85.7 \%$, respectively), ${ }^{26,38}$ and Barnard et al. also found females to be predominantly in these stages $(62.9 \%){ }^{38}$

The present study was unique in evaluating PAPM stages for both parents of girls and boys. The literature has primarily focused on parents of girls, ${ }^{35,37-44}$ with none using the PAPM. We found a significant association between child's gender and PAPM stage of decision-making, with parents of boys more likely to be in earlier PAPM stages, a finding similar to results from other studies. ${ }^{35,37,39-41}$

Multinomial analyses highlighted some important correlates across all PAPM stages as well as some correlates that are particularly important for specific stages. Overall, this study 
found that parents of daughters (compared to sons), of older children, and parents with a HCP recommendation had decreased odds of being in any earlier PAPM stage as compared to the last PAPM stage (i.e. vaccinated). The importance of a HCP recommendation in making the decision regarding HPV vaccination is a well-established finding. ${ }^{11,12,16,35,37,41,45}$ This study contributes to the literature by highlighting that a HCP recommendation is a significant and important differential factor between parents who are 'hesitant' (unengaged, undecided, and decided not; Stages 2-4) and 'acceptors' (decided to vaccinate and vaccinated; Stages 5-6), but not a significant differential factors between acceptor groups (Stages 5 and 6). This suggests that while a HCP recommendation may increase the likelihood that a parent accepts HPV vaccination; a $\mathrm{HCP}$ recommendation alone may not be sufficient to move parents from deciding to vaccinate their child (Stage 5) to having vaccinated their child (Stage 6).

The relationship between knowledge and uptake has previously yielded mixed results (as high and low knowledge have been associated with vaccination). ${ }^{12,46}$ Application of the PAPM model shows that low HPV vaccine knowledge is an important correlate of early stages of decision-making (as compared to vaccinated). Interestingly, in the multivariate analysis parents who had decided not to vaccinate their child had significantly higher HPV vaccine knowledge than parents who vaccinated their child. Accordingly, education interventions alone may not be sufficient for HPV vaccination.

In line with previous research, this study found perceived benefits, barriers-harms, and cues to action were key correlates of PAPM stage. ${ }^{12}$ Previous research using a binary outcome has reported mixed findings regarding the relationship between HPV vaccination with perceived severity and susceptibility of HPV infection and associated disease. ${ }^{12,31}$ By using a nuanced framework of decision-making, this study highlights that, when taking all other variables into account, susceptibility and severity were not significant correlates of earlier PAPM stages except for the 'decided not to vaccinate' stage (Stage 4). Future research should use these findings to investigate theoretically informed interventions to specifically target subsets of the population (by child's gender and decision-making stage), with particular attention towards addressing knowledge gaps, perceived barriers, and concerns of parents.

Interestingly, parents of boys (but not parents of girls) living in provinces with HPV vaccination programs for boys had significantly lower odds of being in early PAPM stages, emphasizing the importance of publicly funded HPV vaccine programs for boys. 


\section{Study strengths and limitations}

This study is unique in examining and comparing HPV vaccine decision-making in Canadian parents of boys and girls using two well-established theoretical frameworks (i.e. the HBM and the PAPM), which captures decision-making in a nuanced and precise way. This is the first study to use the PAPM to evaluate HPV vaccine decision-making in parents of girls and boys. Strengths of the study also include a large sample size, data cleaning techniques that eliminated careless responders, and a nationally representative sample. ${ }^{20}$ This study's questionnaire benefited from the use of intelligent programming to personalize survey items, administration in either English or French, avoiding any missing data, the use of psychometrically validated scales, and the randomization of items within scales to reduce the possibility of an order effect. ${ }^{20}$

This study is not without limitations. The cross-sectional design makes it impossible to determine causality. Although we had a reasonable response rate (67.9\%), there remains the potential that there were similarities between non-responders that could influence the representativeness of the sample. Furthermore, although the sample was generally representative of the Canadian population, it was slightly wealthier, more educated, and White (as compared to the 2016 Census).$^{47}$ This study was also not able to recruit many participants living in Canada's territories, due to constraints in Leger's panel. Future research is needed to replicate this study's conceptual framework and findings to specifically investigate HPV vaccination in disadvantaged populations, as well as in other countries or in cross-country comparisons.

It is also possible that the measurement of HCP recommendation in this study overlooked parents who were recommended the vaccine by a HCP but had not seen or discussed the HPV vaccine with a HCP (e.g. via a letter that was sent home). Moreover, the scope of variables assessed is limited, there are other familial, sociological, environmental, and communication factors that were not included. Specifically, future research should consider the impact of having an older child who was eligible for, or received, the HPV vaccine. Future research should also further examine the impact of publicly funded HPV vaccination programs on parents' decisionmaking. 


\section{Conclusions}

HPV vaccination remains low in Canada. Using a stage-based model of decision-making, this study found that only a quarter of parents were in the final PAPM stage. Parents of daughters, older children, and those with a HCP recommendation had decreased odds of being in any earlier PAPM stage. Individual health beliefs as well as cues to action were key correlates of PAPM stage overall; however, the combinations and importance of correlates varied by PAPM stage and child's gender. These findings indicate that it may be important for future interventions to target and tailor health messaging for different groups depending on their stage of decisionmaking. 
Figure 1. An integrated conceptual framework of HPV vaccination

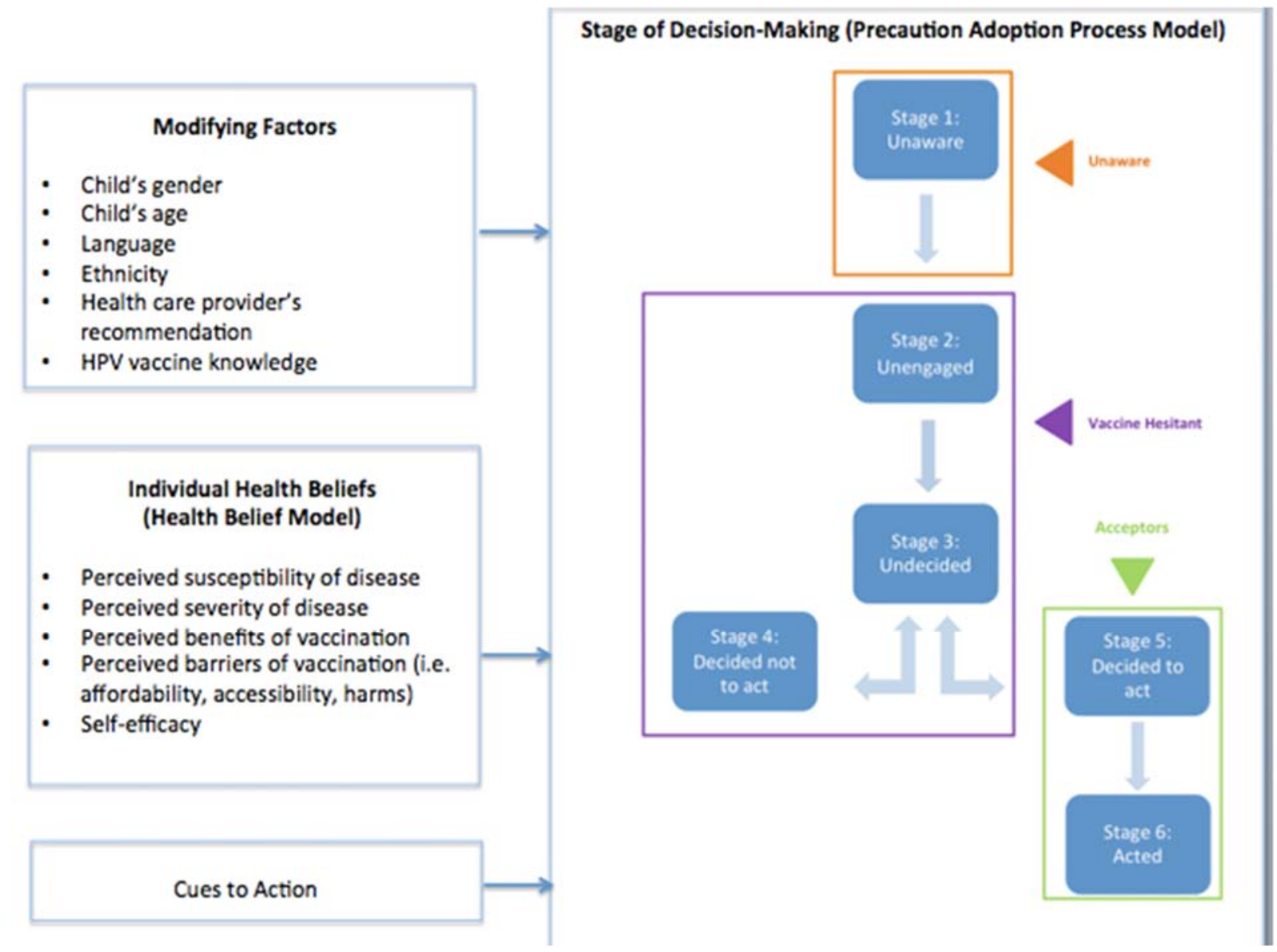

Note. The PAPM, as applied to HPV vaccination, identifies individuals along six stages of decision-making: 1) unaware of the vaccine ("I was unaware that the HPV vaccine could be given to CHILD*"); 2) unengaged in the decision to vaccinate their child ("I have never thought about vaccinating CHILD* against HPV"); 3) undecided about whether to vaccinate their child ("I am undecided about vaccinating CHILD* against HPV"); 4) decided not to act (i.e. decided not to vaccinate their child, "I have decided I DO NOT want to vaccinate CHILD* against HPV"); 5) decided to act (i.e. decided to vaccinate their child, "I have decided I DO want to vaccinate CHILD* against HPV"); and 6) acted (i.e. vaccinated their child, "CHILD* has already received the HPV vaccine"). *To increase the personalization of this questionnaire, intelligent programming allowed for each question with "CHILD" to specifically include their child's name. 
Table 1. Sample Characteristic $(N=3,779)$

\begin{tabular}{|c|c|}
\hline Participant Characteristics & $N(\%)$ \\
\hline \multicolumn{2}{|l|}{ Parent's gender } \\
\hline Men & $1,311(34.69)$ \\
\hline Women & $2,468(65.31)$ \\
\hline \multicolumn{2}{|l|}{ Parent's age } \\
\hline Range (years) & $18-81$ \\
\hline Mean $(S D)$ & $43.51(6.86)$ \\
\hline \multicolumn{2}{|c|}{ Language in which parents answered the survey } \\
\hline English & $2,801(74.12)$ \\
\hline French & $978(25.88)$ \\
\hline \multicolumn{2}{|l|}{ Marital status } \\
\hline Single/Separated/divorced/widowed & $760(20.11)$ \\
\hline Married/common law & $3,019(79.89)$ \\
\hline \multicolumn{2}{|l|}{ Parent's level of education } \\
\hline Elementary or high school & $659(17.44)$ \\
\hline Trade technical or university & $3,120(82.56)$ \\
\hline \multicolumn{2}{|l|}{ Parent's employment status } \\
\hline Employed & $3,057(80.89)$ \\
\hline Not employed & $722(19.11)$ \\
\hline \multicolumn{2}{|l|}{ Born in Canada } \\
\hline Yes & $3,214(85.05)$ \\
\hline No & $565(14.95)$ \\
\hline \multicolumn{2}{|l|}{ Parent's ethnicity } \\
\hline White & $3,224(85.31)$ \\
\hline Other & $555(14.69)$ \\
\hline \multicolumn{2}{|l|}{ Parent's religion } \\
\hline Any religious affiliation & $2,493(65.97)$ \\
\hline No religious affiliation & $1,286(34.03)$ \\
\hline \multicolumn{2}{|l|}{ Household income } \\
\hline$<100 \mathrm{~K}$ & $1,973(52.21)$ \\
\hline$\geq 100 \mathrm{~K}$ & $1,409(37.28)$ \\
\hline Prefer not to answer & $397(10.51)$ \\
\hline \multicolumn{2}{|l|}{ Child's gender } \\
\hline Boys (sons) & $1,826(48.32)$ \\
\hline Girls (daughters) & $1,953(51.68)$ \\
\hline \multicolumn{2}{|l|}{ Child's age } \\
\hline Range (years) & $9-16$ \\
\hline Mean $(S D)$ & $12.58(2.31)$ \\
\hline \multicolumn{2}{|l|}{ Child's school's religion } \\
\hline No affiliation & $2,821(74.65)$ \\
\hline Any religious affiliation & $958(25.35)$ \\
\hline \multicolumn{2}{|l|}{ Child's school's language } \\
\hline English & $2,647(70.04)$ \\
\hline French and Other & $1,132(29.96)$ \\
\hline
\end{tabular}


Province with funded HPV vaccination for boys

No

$3,225(85.34)$

Yes

$554(14.66)$

Size of city

$<100 \mathrm{~K}$

$1,799(47.61)$

$\geq 100 \mathrm{~K}$

$1,980(52.39)$

Number of children in the family

1

2

868 (22.97)

$\geq 3$

$1,747(46.23)$

$1,164(30.80)$

Child's sexual orientation

Heterosexual

$3,301(87.35)$

Other

$478(12.65)$

HCP recommendation

No

3,346 (88.54)

Yes 
Table 2. Parents' PAPM stage by child's gender

\begin{tabular}{l|c|c|c|c}
\hline \multicolumn{1}{c|}{ PAPM Stage } & $\begin{array}{c}\text { Parents of girls } \\
(n=1,953)\end{array}$ & $\begin{array}{c}\text { Parents of boys } \\
(n=1,826)\end{array}$ & $\begin{array}{c}\text { Test of } \\
\text { proportions girls } \\
\text { versus boys }\end{array}$ & $\begin{array}{c}\text { All parents } \\
(N=3,779)\end{array}$ \\
\hline $\begin{array}{l}\text { Stage 1- } \\
\text { Unaware }\end{array}$ & $n(\%)$ & $n(\%)$ & $95 \%$ CI & $N(\%)$ \\
$\begin{array}{l}\text { Stage 2- } \\
\text { Unengaged }\end{array}$ & $97(5.0)$ & $298(16.3)$ & $-13.30 ;-9.40$ & $395(10.5)$ \\
$\begin{array}{l}\text { Stage 3- } \\
\text { Undecided }\end{array}$ & $291(14.9)$ & $389(21.3)$ & $-8.86 ;-3.94$ & $680(16.0)$ \\
$\begin{array}{l}\text { Stage 4- } \\
\text { Decided NOT }\end{array}$ & $191(9.8)$ & $162(8.9)$ & $-0.95 ; 2.76$ & $353(9.3)$ \\
$\begin{array}{l}\text { Stage 5- } \\
\text { Decided YES }\end{array}$ & $437(22.4)$ & $349(19.1)$ & $0.68 ; 5.85$ & $786(20.8)$ \\
$\begin{array}{l}\text { Stage 6- } \\
\text { Vaccinated }\end{array}$ & $801(41.0)$ & $160(8.8)$ & $29.71 ; 34.79$ & $961(25.4)$ \\
\hline
\end{tabular}


Table 3. Comparison of parents' vaccine knowledge and attitudes by PAPM stage

\begin{tabular}{|c|c|c|c|c|c|c|c|c|c|}
\hline Scale & $\begin{array}{c}\text { Total } \\
N=3,779 \\
M(S D)\end{array}$ & $\begin{array}{c}\text { Stage 1- } \\
\text { Unaware } \\
n=604 \\
M(S D)\end{array}$ & $\begin{array}{c}\text { Stage 2- } \\
\text { Unengaged } \\
n=395 \\
M(S D)\end{array}$ & $\begin{array}{c}\text { Stage 3- } \\
\text { Undecided } \\
n=680 \\
M(S D)\end{array}$ & $\begin{array}{c}\text { Stage 4- } \\
\text { Decided NOT } \\
n=353 \\
M(S D)\end{array}$ & $\begin{array}{c}\text { Stage 5- } \\
\text { Decided YES } \\
n=786 \\
M(S D)\end{array}$ & $\begin{array}{c}\text { Stage 6- } \\
\text { Vaccinated } \\
n=961 \\
M(S D)\end{array}$ & $\begin{array}{c}\text { ANOVA } F \\
\text { test- } \\
\text { statistic }\end{array}$ & $\begin{array}{c}\text { Effect } \\
\text { size }(\omega)\end{array}$ \\
\hline $\begin{array}{l}H P V \text { Vaccine K } \\
\text { HPV General } \\
\text { Knowledge }\end{array}$ & $\begin{array}{l}\text { ledge } \\
12.79(6.07)\end{array}$ & $8.53(6.51)^{\mathrm{a}}$ & $11.34(5.97)^{\mathbf{b}}$ & $12.95(5.77)^{\mathrm{c}}$ & $14.88(5.45)^{d}$ & $14.33(5.39)^{\mathrm{d}}$ & $13.93(5.32)^{d}$ & 101.32 & 0.34 \\
\hline $\begin{array}{l}\text { HPV Vaccine } \\
\text { Knowledge } \\
H P V \text {-specific } H\end{array}$ & $\begin{array}{l}6.01(2.92) \\
\text { attitudes }\end{array}$ & $3.76(3.07)^{\mathrm{a}}$ & $4.85(2.97)^{b}$ & $5.89(2.75)^{\mathbf{c}}$ & $6.88(2.55)^{d}$ & $6.74(2.48)^{d}$ & $7.06(2.37)^{d}$ & 149.95 & 0.41 \\
\hline Susceptibility & $4.93(1.38)$ & $4.73(1.16)^{\mathrm{a}}$ & $4.61(1.16)^{a, b}$ & $4.50(1.08)^{b}$ & $3.00(1.37)^{\mathbf{c}}$ & $5.65(1.09)^{d}$ & $5.64(1.05)^{d}$ & 382.00 & 0.58 \\
\hline Severity & $5.91(1.08)$ & $5.84(1.08)^{\mathrm{a}}$ & $5.82(1.05)^{\mathrm{a}}$ & $5.83(1.06)^{\mathrm{a}}$ & $5.18(1.39)^{\mathbf{b}}$ & $6.15(0.94)^{\mathrm{c}}$ & $6.13(0.96)^{\mathrm{c}}$ & 53.11 & 0.25 \\
\hline Benefits & $4.90(1.14)$ & $4.87(0.95)^{\mathrm{a}}$ & $4.75(0.93)^{\mathbf{a}, \mathbf{b}}$ & $4.58(0.86)^{\mathbf{b}}$ & $3.10(1.06)^{\mathrm{c}}$ & $5.57(0.86)^{d}$ & $5.33(0.91)^{\mathrm{e}}$ & 421.15 & 0.60 \\
\hline $\begin{array}{l}\text { Barriers-not } \\
\text { affordable }\end{array}$ & $3.61(1.70)$ & $4.70(1.33)^{\mathrm{a}}$ & $4.35(1.37)^{b}$ & $4.16(1.52)^{b}$ & $3.09(1.56)^{\mathrm{c}}$ & $3.78(1.64)^{d}$ & $2.30(1.31)^{\mathrm{e}}$ & 275.65 & 0.52 \\
\hline $\begin{array}{l}\text { Barriers-not } \\
\text { accessible }\end{array}$ & $2.85(1.15)$ & $3.57(0.92)^{\mathrm{a}}$ & $3.35(0.98)^{\mathbf{a}, \mathbf{b}}$ & $3.18(1.02)^{b}$ & $2.86(1.16)^{\mathrm{c}}$ & $2.65(1.12)^{\mathrm{c}}$ & $2.15(0.99)^{d}$ & 188.42 & 0.45 \\
\hline Barriers-harms & $3.54(1.42)$ & $3.74(1.07)^{\mathrm{a}}$ & $3.82(1.10)^{\mathrm{a}}$ & $4.18(1.12)^{b}$ & $5.50(1.21)^{\mathrm{c}}$ & $2.85(1.17)^{d}$ & $2.68(1.12)^{d}$ & 433.92 & 0.60 \\
\hline Cues to action & $4.62(1.16)$ & $4.14(0.88)^{\mathrm{a}}$ & $3.98(0.88)^{\mathrm{a}}$ & $4.06(0.79)^{\mathrm{a}}$ & $3.43(1.02)^{b}$ & $5.11(0.94)^{\mathbf{c}}$ & $5.61(0.85)^{d}$ & 554.38 & 0.65 \\
\hline Self efficacy & $6.00(1.01)$ & $5.63(1.10)^{\mathrm{a}}$ & $5.65(1.09)^{\mathrm{a}}$ & $5.67(1.03)^{\mathrm{a}}$ & $6.29(1.00)^{b}$ & $6.27(0.82)^{\mathbf{b}}$ & $6.28(0.83)^{b}$ & 79.45 & 0.31 \\
\hline \multicolumn{10}{|c|}{ General Vaccine Attitudes } \\
\hline VCBS & $3.23(1.44)$ & $3.46(1.36)^{\mathrm{a}}$ & $3.40(1.38)^{\mathrm{a}}$ & $3.56(1.35)^{\mathrm{a}}$ & $4.70(1.35)^{b}$ & $2.66(1.31)^{\mathrm{c}}$ & $2.73(1.21)^{\mathrm{c}}$ & 160.04 & 0.42 \\
\hline $\begin{array}{l}\text { VHS-Lack of } \\
\text { Confidence }\end{array}$ & $1.98(0.72)$ & $2.04(0.66)^{\mathrm{a}}$ & $2.07(0.64)^{\mathrm{a}}$ & $2.13(0.65)^{\mathrm{a}}$ & $2.84(0.91)^{\mathbf{b}}$ & $1.69(0.57)^{\mathbf{c}}$ & $1.74(0.54)^{\mathbf{c}}$ & 196.69 & 0.45 \\
\hline VHS-Risks & $3.07(0.95)$ & $3.15(0.85)^{\mathrm{a}}$ & $3.14(0.86)^{\mathrm{a}}$ & $3.38(0.87)^{\mathbf{b}}$ & $3.90(0.83)^{\mathbf{c}}$ & $2.75(0.94)^{d}$ & $2.74(0.85)^{d}$ & 132.25 & 0.38 \\
\hline
\end{tabular}

Note. All skewness and kurtosis are less than 2. VHS scales are measured 1-5; all other scales are measured 1-7. All one-way independent groups ANOVA were significant (all $p<.001)$. Effect sizes $(\omega)$ are presented for each ANOVA analysis. Post hoc tests were conducted using Tukey HSD. For each scale, groups that were not significantly different $(p<.01)$ from each other in post hoc tests are in the same group (notated using a superscript, e.g. ${ }^{\text {a }}$ ). 
Table 4. Bivariate multinomial logistic regression analysis of parents' PAPM stage $(N=3,779)$

\begin{tabular}{|c|c|c|c|c|c|}
\hline Variables & $\begin{array}{c}\text { Stage 1-Unaware } \\
\text { OR } \\
(95 \% \mathrm{CI}) \\
n=604\end{array}$ & $\begin{array}{c}\text { Stage 2-Unengaged } \\
\text { OR } \\
(95 \% \mathrm{CI}) \\
n=395\end{array}$ & $\begin{array}{c}\text { Stage 3-Undecided } \\
\text { OR } \\
(95 \% \mathrm{CI}) \\
n=680\end{array}$ & $\begin{array}{c}\text { Stage 4-Decided } \\
\text { NOT } \\
\text { OR } \\
(95 \% \mathrm{CI}) \\
n=353 \\
\end{array}$ & $\begin{array}{c}\text { Stage 5-Decided YES } \\
\text { OR } \\
(95 \% \mathrm{CI}) \\
n=786\end{array}$ \\
\hline \multicolumn{6}{|l|}{ Child's gender } \\
\hline Male & (reference) & (reference) & (reference) & (reference) & (reference) \\
\hline Female & $0.06(0.04 ; 0.07)$ & $0.07(0.05 ; 0.09)$ & $0.15(0.12 ; 0.19)$ & $0.24(0.18 ; 0.31)$ & $0.25(0.20 ; 0.31)$ \\
\hline Child's age (One-year increase) & $0.73(0.69 ; 0.76)$ & $0.80(0.76 ; 0.84)$ & $0.76(0.73 ; 0.79)$ & $0.81(0.76 ; 0.85)$ & $0.71(0.68 ; 0.75)$ \\
\hline \multicolumn{6}{|l|}{ Language parents answered the survey } \\
\hline English & (reference) & (reference) & (reference) & (reference) & (reference) \\
\hline French & $1.26(1.02 ; 1.57)$ & $0.65(0.49 ; 0.85)$ & $0.56(0.45 ; 0.71)$ & $0.87(0.67 ; 1.14)$ & $0.48(0.38 ; 0.60)$ \\
\hline \multicolumn{6}{|l|}{ Parent's ethnicity } \\
\hline Other & (reference) & (reference) & (reference) & (reference) & (reference) \\
\hline White & $0.64(0.48 ; 0.86)$ & $0.61(0.44 ; 0.85)$ & $0.75(0.56 ; 0.99)$ & $0.90(0.62 ; 1.31)$ & $0.71(0.54 ; 0.94)$ \\
\hline \multicolumn{6}{|l|}{ HCP recommendation } \\
\hline No & (reference) & (reference) & (reference) & (reference) & (reference) \\
\hline Yes & $0.01(0.01 ; 0.05)$ & $0.09(0.04 ; 0.17)$ & $0.32(0.24 ; 0.45)$ & $0.43(0.29 ; 0.62)$ & $0.74(0.58 ; 0.95)$ \\
\hline $\begin{array}{l}\text { HPV Vaccine knowledge } \\
\text { (One-unit increase) }\end{array}$ & $0.66(0.64 ; 0.69)$ & $0.74(0.71 ; 0.78)$ & $0.84(0.81 ; 0.87)$ & $0.97(0.92 ; 1.02)$ & $0.95(0.91 ; 0.98)$ \\
\hline Susceptibility (One-unit increase) & $0.47(0.43 ; 0.52)$ & $0.43(0.39 ; 0.48)$ & $0.40(0.36 ; 0.44)$ & $0.16(0.14 ; 0.18)$ & $1.01(0.92 ; 1.10)$ \\
\hline Severity (One-unit increase) & $0.75(0.68 ; 0.83)$ & $0.74(0.66 ; 0.82)$ & $0.74(0.67 ; 0.82)$ & $0.48(0.43 ; 0.54)$ & $1.03(0.93 ; 1.14)$ \\
\hline Benefits (One-unit increase) & $0.57(0.50 ; 0.63)$ & $0.49(0.42 ; 0.56)$ & $0.39(0.35 ; 0.44)$ & $0.08(0.07 ; 0.1)$ & $1.36(1.22 ; 1.51)$ \\
\hline Barriers-Affordability (One-unit increase) & $3.03(2.78 ; 3.30)$ & $2.59(2.37 ; 2.83)$ & $2.38(2.20 ; 2.57)$ & $1.49(1.37 ; 1.63)$ & $2.02(1.88 ; 2.17)$ \\
\hline Barriers-Accessibility (One-unit increase) & $3.74(3.34 ; 4.20)$ & $3.02(2.67 ; 3.42)$ & $2.60(2.34 ; 2.88)$ & $1.95(1.73 ; 2.19)$ & $1.60(1.46 ; 1.76)$ \\
\hline Barriers-Harms (One-unit increase) & $2.22(2.02 ; 2.44)$ & $2.36(2.11 ; 2.63)$ & $3.12(2.82 ; 3.45)$ & $8.85(7.60 ; 10.31)$ & $1.14(1.05 ; 1.24)$ \\
\hline Cues to action (One-unit increase) & $0.15(0.13 ; 0.17)$ & $0.12(0.10 ; 0.14)$ & $0.13(0.11 ; 0.15)$ & $0.06(0.05 ; 0.07)$ & $0.55(0.50 ; 0.62)$ \\
\hline Self-Efficacy (One-unit increase) & $0.50(0.45 ; 0.56)$ & $0.51(0.45 ; 0.57)$ & $0.51(0.46 ; 0.57)$ & $1.02(0.88 ; 1.19)$ & $0.99(0.88 ; 1.11)$ \\
\hline $\begin{array}{l}\text { Vaccine conspiracy beliefs (One-unit } \\
\text { increase) }\end{array}$ & $1.51(1.40 ; 1.64)$ & $1.47(1.34 ; 1.60)$ & $1.60(1.48 ; 1.73)$ & $3.10(2.78 ; 3.46)$ & $0.96(0.89 ; 1.03)$ \\
\hline $\begin{array}{l}\text { Hesitancy-Lack of Confidence (One-unit } \\
\text { increase) }\end{array}$ & $2.34(1.97 ; 2.79)$ & $2.49(2.05 ; 3.03)$ & $2.86(2.42 ; 3.38)$ & $9.21(7.50 ; 11.31)$ & $0.86(0.72 ; 1.02)$ \\
\hline Hesitancy-Risks (One-unit increase) & $1.69(1.50 ; 1.90)$ & $1.65(1.44 ; 1.89)$ & $2.31(2.05 ; 2.61)$ & $5.19(4.38 ; 6.16)$ & $1.01(0.91 ; 1.12)$ \\
\hline
\end{tabular}

Note. The reference category for PAPM stage is 'Stage 6-Vaccinated' $(n=961)$. OR $=$ odds ratio. $95 \% \mathrm{CI}=95 \%$ confidence interval. HCP $=$ health care provider. 
Table 5. Multivariate multinomial logistic regression analysis of parents' PAPM stage $(N=3,779)$

\begin{tabular}{|c|c|c|c|c|c|}
\hline Variables & $\begin{array}{c}\text { Stage 1-Unaware } \\
\text { AOR }(95 \% \mathrm{CI}) \\
n=604\end{array}$ & $\begin{array}{c}\text { Stage 2-Unengaged } \\
\text { AOR }(95 \% \mathrm{CI}) \\
n=395\end{array}$ & $\begin{array}{c}\text { Stage 3-Undecided } \\
\text { AOR }(95 \% \mathrm{CI}) \\
n=680\end{array}$ & $\begin{array}{c}\text { Stage 4-Decided } \\
\text { NOT } \\
\text { AOR }(95 \% \mathrm{CI}) \\
n=353\end{array}$ & $\begin{array}{c}\text { Stage 5-Decided } \\
\text { YES } \\
\text { AOR }(95 \% \mathrm{CI}) \\
\mathrm{n}=786\end{array}$ \\
\hline \multicolumn{6}{|l|}{ Child's gender } \\
\hline Male & (reference) & (reference) & (reference) & (reference) & (reference) \\
\hline Female & $0.15(0.11 ; 0.21)$ & $0.15(0.11 ; 0.22)$ & $0.33(0.24 ; 0.45)$ & $0.36(0.23 ; 0.57)$ & $0.49(0.37 ; 0.65)$ \\
\hline Child's age (One-year increase) & $0.63(0.59 ; 0.67)$ & $0.69(0.65 ; 0.74)$ & $0.68(0.64 ; 0.73)$ & $0.80(0.74 ; 0.88)$ & $0.64(0.60 ; 0.67)$ \\
\hline \multicolumn{6}{|l|}{ Language parents answered the survey } \\
\hline English & (reference) & (reference) & (reference) & (reference) & (reference) \\
\hline French & $1.21(0.87 ; 1.69)$ & $0.67(0.47 ; 0.97)$ & $0.61(0.44 ; 0.84)$ & $0.91(0.58 ; 1.43)$ & $0.51(0.38 ; 0.67)$ \\
\hline \multicolumn{6}{|l|}{ Parent's ethnicity } \\
\hline Other & (reference) & (reference) & (reference) & (reference) & (reference) \\
\hline White & $1.37(0.91 ; 2.06)$ & $1.28(0.84 ; 1.96)$ & $1.62(1.10 ; 2.39)$ & $1.16(0.65 ; 2.05)$ & $1.31(0.93 ; 1.84)$ \\
\hline \multicolumn{6}{|l|}{ HCP recommendation } \\
\hline No & (reference) & (reference) & (reference) & (reference) & (reference) \\
\hline Yes & $0.04(0.01 ; 0.16)$ & $0.21(0.10 ; 0.43)$ & $0.55(0.36 ; 0.84)$ & $0.30(0.15 ; 0.61)$ & $0.89(0.66 ; 1.20)$ \\
\hline $\begin{array}{l}\text { HPV Vaccine knowledge } \\
\text { (One-unit increase) }\end{array}$ & $0.75(0.71 ; 0.79)$ & $0.86(0.81 ; 0.91)$ & $0.98(0.93 ; 1.04)$ & $1.12(1.04 ; 1.22)$ & $0.96(0.91 ; 1.01)$ \\
\hline Susceptibility (One-unit increase) & $0.97(0.81 ; 1.17)$ & $0.98(0.81 ; 1.18)$ & $0.89(0.75 ; 1.05)$ & $0.68(0.55 ; 0.84)$ & $1.06(0.91 ; 1.23)$ \\
\hline Severity (One-unit increase) & $1.06(0.91 ; 1.25)$ & $1.06(0.90 ; 1.25)$ & $1.08(0.93 ; 1.25)$ & $0.66(0.54 ; 0.80)$ & $1.02(0.89 ; 1.16)$ \\
\hline Benefits (One-unit increase) & $1.89(1.48 ; 2.41)$ & $1.62(1.26 ; 2.08)$ & $1.40(1.12 ; 1.74)$ & $0.60(0.45 ; 0.81)$ & $2.10(1.72 ; 2.55)$ \\
\hline Barriers-Affordability (One-unit increase) & $1.99(1.76 ; 2.24)$ & $1.62(1.43 ; 1.84)$ & $1.70(1.52 ; 1.90)$ & $1.22(1.03 ; 1.43)$ & $1.68(1.53 ; 1.84)$ \\
\hline Barriers-Accessibility (One-unit increase) & $1.50(1.27 ; 1.78)$ & $1.26(1.05 ; 1.50)$ & $1.10(0.94 ; 1.29)$ & $1.07(0.85 ; 1.34)$ & $1.14(0.99 ; 1.31)$ \\
\hline Barriers-Harms (One-unit increase) & $1.53(1.31 ; 1.78)$ & $1.68(1.43 ; 1.97)$ & $2.19(1.90 ; 2.52)$ & $3.50(2.85 ; 4.28)$ & $1.15(1.01 ; 1.30)$ \\
\hline Cues to action (One-unit increase) & $0.27(0.22 ; 0.34)$ & $0.20(0.16 ; 0.25)$ & $0.24(0.19 ; 0.29)$ & $0.21(0.16 ; 0.28)$ & $0.51(0.43 ; 0.61)$ \\
\hline Self-Efficacy (One-unit increase) & $1.10(0.91 ; 1.33)$ & $1.16(0.96 ; 1.40)$ & $1.11(0.93 ; 1.32)$ & $1.87(1.49 ; 2.35)$ & $1.24(1.04 ; 1.48)$ \\
\hline
\end{tabular}




\section{References}

1. Brotherton JML, Zuber F, Bloem PJN. Primary Prevention of HPV through Vaccination: Update on Current Global Status. Curr Obst Gynecol Reports. 2016;5:210-224.

2. Canadian Cancer Society. Canadian Cancer Statistics 2016. 2016.

3. Shapiro GK, Guichon J, Kelaher M. Canadian school-based HPV vaccine programs and policy considerations. Vaccine. 2017; 35:5700-5707.

4. Blake DR, Middleman AB. Human Papillomavirus Vaccine Update. Pediatric clinics of North America. Apr 2017;64(2):321-329.

5. Brotherton JML, Bloem PJN. HPV Vaccination: Current Global Status. Curr Obstet Gynecol Rep. 2015;4:220-233.

6. Cervical Cancer Action. Global Progress in HPV Vaccination. 2017; http://www.cervicalcanceraction.org/comments/comments3.php. Accessed July 20, 2018.

7. Shapiro GK, Perez S, Rosberger Z. Including males in Canadian human papillomavirus vaccination programs: a policy analysis. Canadian Medical Association Journal. 2016;188(12):881-886.

8. Shapiro GK, Guichon J, Prue G, Perez S, Rosberger Z. A Multiple Streams analysis of the decisions to fund gender-neutral HPV vaccination in Canada. Prev Med. Apr 20 2017;100:123-131.

9. Public Health Agency of Canada. Canada's Provincial and Territorial Routine (and Catch-up) Vaccination Programs for Infants and Children. In: Canadian Immunization Guide, ed2017.

10. Shapiro G, Guichon J, Perez S, Rosberger Z. British Columbia's flawed HPV vaccination policy. Policy Options [Internet]. 2015 Sep 25;

http://policyoptions.irpp.org/issues/september-2015/british-columbias-flawedhpv-vaccination-policy/.

11. Holman DM, Benard V, Roland KB, Watson M, Liddon N, Stokley S. Barriers to Human Papillomavirus Vaccination Among US Adolescents: A Systematic Review of the Literature. JAMA pediatrics. 2014; 168 (1):76-82.

12. Radisic G, Chapman J, Flight I, Wilson C. Factors associated with parents' attitudes to the HPV vaccination of their adolescent sons : A systematic review. Prev Med. Feb 2017;95:26-37.

13. Gerend MA, Shepherd JE. Predicting human papillomavirus vaccine uptake in young adult women: comparing the health belief model and theory of planned behavior. Annals of behavioral medicine : a publication of the Society of Behavioral Medicine. Oct 2012;44(2):171-180.

14. Shapiro GK, Holding A, Perez S, Amsel R, Rosberger Z. Validation of the vaccine conspiracy beliefs scale. Papillomavirus Research. 12// 2016;2:167-172.

15. Shapiro GK, Tatar O, Dube E, et al. The Vaccine Hesitancy Scale: Psychometric properties and validation. Vaccine. 2018;36:545-552.

16. Perez S, Tatar O, Gilca V, et al. Untangling the psychosocial predictors of HPV vaccination decision-making among parents of boys. Vaccine. Aug 24 2017;35(36):4713-4721.

17. Perez S, Shapiro GK, Tatar O, Joyal-Desmarais K, Rosberger Z. Development and 
validation of the HPV Attitudes and Beliefs Scale (HABS) in a National Canadian sample. Sexually Transmitted Diseases. 2016;43(10):626-632.

18. Shapiro GK, Surian D, Dunn A, Perry R, Kelaher M. HPV vaccine concern on Twitter: A cross-country analysis in Australia, Canada and the UK. BMJ Open. 2017;7:e016869.

19. Dube E, Laberge C, Guay M, Bramadat P, Roy R, Bettinger J. Vaccine hesitancy: An overview. Human Vaccines \& Immunotherapeutics. 2013;9(8):1763-1773.

20. Shapiro GK, Perez S, Naz A, et al. Investigating Canadian parents' HPV vaccine knowledge, attitudes, and behaviour: A study protocol for a longitudinal national online survey. BMJ Open. 2017;7:e017814.

21. Weinstein ND. The precaution adoption process. Health Psychol. 1988;7(4):355386.

22. Prue G, Santin O. HPV vaccine acceptance in male adolescents. Psychooncology. Aug 28 2015;24(10):1327-1329.

23. Weinstein ND, Sandman PM. A model of the precaution adoption process: evidence from home radon testing. Health Psychol. 1992;11(3):170-180.

24. Barnard M, George P, Perryman ML, Wolff LA. Human papillomavirus (HPV) vaccine knowledge, attitudes, and uptake in college students: Implications from the Precaution Adoption Process Model. PloS one. 2017;12(8): 0182266.

25. Perez S, Tatar O, Shapiro GK, et al. Psychosocial determinants of parental human papillomavirus (HPV) vaccine decision-making for sons: Methodological challenges and initial results of a pan-Canadian longitudinal study. BMC Public Health. Dec 05 2016;16(1):1223.

26. Tatar O, Perez S, Naz A, Shapiro GK, Rosberger Z. Psychosocial correlates of HPV vaccine acceptability in college males: A cross-sectional exploratory study. Papillomavirus research (Amsterdam, Netherlands). Dec 2017;4:99-107.

27. Leger. Marketing Research and Surveys. 2018; http://leger360.com/enca/servicesurveyadvice. Accessed April 24, 2018.

28. Waller J, Ostini R, Marlow LA, McCaffery K, Zimet G. Validation of a measure of knowledge about human papillomavirus (HPV) using item response theory and classical test theory. Preventive medicine. 2013;56(1):35-40.

29. Perez S, Tatar O, Ostini R, et al. Extending and validating a human papillomavirus (HPV) knowledge measure in a national sample of Canadian parents of boys. Prev Med. Oct 2016;91:43-49.

30. Larson HJ, Jarretta C, Schulza WS, et al. Measuring vaccine hesitancy: The development of a survey tool. Vaccine. 2015;33(34):4165-4175.

31. Krawczyk A, Knauper B, Gilca V, et al. Parents' decision-making about the human papillomavirus vaccine for their daughters: I. Quantitative results. Human Vaccines \& Immunotherapeutics. 2015;11(2):322-329.

32. Cohen J. Quantitative methods in psychology: A power primer. Psychological Bulletin. 1992;112(1):155-159.

33. Gilbert NL, Gilmour H, Dubé E, Wilson SE, Laroche J. Estimates and determinants of HPV non-vaccination and vaccine refusal in girls 12 to 14 years of age in Canada: Results from the Childhood National Immunization Coverage Survey, 2013. Human Vaccines \& Immunotherapeutics. 2016;12(6):1484-1490.

34. Sherman SM, Nailer E. Attitudes towards and knowledge about Human 
Papillomavirus (HPV) and the HPV vaccination in parents of teenage boys in the UK. PloS one. 2018;13(4): 0195801.

35. Loke AY, Kwan ML, Wong YT, Wong AKY. The Uptake of Human Papillomavirus Vaccination and Its Associated Factors Among Adolescents: A Systematic Review. Journal of primary care \& community health. Oct 2017;8(4):349-362.

36. Bird Y, Obidiya O, Mahmood R, Nwankwo C, Moraros J. Human Papillomavirus Vaccination Uptake in Canada: A Systematic Review and Meta-analysis. International journal of preventive medicine. 2017;8:71.

37. Johnson KL, Lin MY, Cabral H, Kazis LE, Katz IT. Variation in Human Papillomavirus Vaccine Uptake and Acceptability Between Female and Male Adolescents and Their Caregivers. Journal of community health. Jun 2017;42(3):522-532.

38. Barnard M. Human papillomavirus (HPV) vaccine knowledge, attitudes, and uptake in college students: Implications from the Precaution Adoption Process Model. Hum Vaccin Immunother. 2017;12(8):e0182266.

39. Finney Rutten LJ, St Sauver JL, Beebe TJ, et al. Association of both consistency and strength of self-reported clinician recommendation for HPV vaccination and HPV vaccine uptake among 11- to 12-year-old children. Vaccine. Oct 27 2017;35(45):6122-6128.

40. Hanson KE, Koch B, Bonner K, McRee AL, Basta NE. National Trends in Parental HPV Vaccination Intentions and Reasons for Hesitancy, 2010-2015. Clinical infectious diseases : an official publication of the Infectious Diseases Society of America. Mar 272018.

41. Lindley MC, Jeyarajah J, Yankey D, Curtis CR, Markowitz LE, Stokley S. Comparing human papillomavirus vaccine knowledge and intentions among parents of boys and girls. Hum Vaccin Immunother. Jun 02 2016;12(6):1519-1527.

42. Mohammed KA, Vivian E, Loux TM, Arnold LD. Factors associated with parents' intent to vaccinate adolescents for human papillomavirus: Findings from the 2014 National Immunization Survey-Teen. Preventing chronic disease. Jun 8 2017; 14:E45.

43. VanWormer JJ, Bendixsen CG, Vickers ER, et al. Association between parent attitudes and receipt of human papillomavirus vaccine in adolescents. $B M C$ Public Health. Oct 2 2017;17(1):766.

44. Wang Z, Wang J, Fang Y, et al. Parental acceptability of HPV vaccination for boys and girls aged 9-13 years in China: A population-based study. Vaccine. Mar 29 2018.

45. Gilkey MB, Moss JL, McRee AL, Brewer NT. Do correlates of HPV vaccine initiation differ between adolescent boys and girls? Vaccine. 2012;30:5928-5934.

46. Nickel B, Dodd RH, Turner RM, et al. Factors associated with the human papillomavirus (HPV) vaccination across three countries following vaccination introduction. Preventive medicine reports. Dec 2017;8:169-176.

47. Statistics Canada. Highlight tables, 2016 Census. In: Statistics Canada Catalogue no. 98-316-X2016001, ed. Ottawa2017. 